\title{
As paisagens sonoras de Gertrude Stein: a peça-paisagem na criação de mundos sônicos
}

\section{Gertrude Stein's soundscapes: the landscape play in the making of sonic worlds}

\author{
Alexandre Lautert \\ Especialista em Artes Híbridas pela Universidade Tecnológica Federal do Paraná (UTFPR). Graduado em Artes Cênicas \\ pela Universidade Estadual do Paraná (UNESPAR) - ale.lautert@gmail.com
}

\begin{abstract}
Resumo
A presente pesquisa se propõe a analisar de que modo o conceito dramatúrgico de peça-paisagem de Gertrude Stein, criado na década de 1930, pode ser relacionado ao conceito de paisagem sonora de Raymond Murray Schafer, criado, por sua vez, no fim dos anos 1970. Por meio da revisão das ideias de Stein acerca do teatro do seu tempo, do estudo da sua proposta dramatúrgica própria, das características gerais presentes nos seus textos, e da análise de trecho de uma de suas peças, foi possível verificar a grande importância que a autora dava à sonoridade do que escrevia para tornar possível a construção de instigantes ambientes sônicos por meio da enunciação verbal na cena teatral. Também foi verificada a frequente aproximação dos textos de Gertrude Stein com o aspecto de ruído conforme descrito por Raymond Murray Schafer, apontando para a possibilidade de recepção de suas peças através de um hedonismo do som destituído de qualquer significado semântico.
\end{abstract}

Palavras-chave: Gertrude Stein. Murray Schafer. Peça-paisagem. Paisagem sonora. Ruído.

\begin{abstract}
The present research aims to analyze how Gertrude Stein's dramaturgical concept of landscape play, created in the 1930's, can be related to Raymond Murray Schafer's concept of soundscape, which was created, on the other hand, in the late 1970's. By reviewing Stein's ideas about the theatre of her time, by studying her own dramaturgical proposition, by examining the general characteristics shown on her texts, and by analyzing an excerpt of one of her plays, it was possible to certify the great importance that the author gave to the sonority of what she wrote to make the building of thought-provoking sonic environments possible through verbal enunciation on the theater stage. We were also able to verify a frequent similarity between Gertrude Stein's texts and the aspect of noise as described by Raymond Murray Schafer, bringing to the possibility of the reception of her plays through the pleasure of sound regardless semantics.
\end{abstract}

Keywords: Gertrude Stein. Murray Schafer. Landscape play. Soundscape. Noise.

Recebido em: 27/07/2016

Aceito em: 26/07/2018 


\title{
1 INTRODUÇÃO
}

A escritora norte-americana Gertrude Stein (1874-1946), envolvida com a vanguarda do início do século $X X$, buscou um campo de experimentação poético voltado para a invenção de novas formas de escrita, fato refletido tanto em suas criações artísticas quanto em seus textos teóricos. Residindo em Paris desde seus 29 anos, onde integrou um círculo de amizades composto por nomes como o do pintor Pablo Picasso, Stein desenvolveu sua produção literária em estreita ligação com as artes visuais. Tal característica pode ser percebida já na maneira como a autora categorizou seus escritos, naturezas-mortas e retratos são alguns deles. Ao abordar estes dois tipos de textos criados por Stein, Bowers (2002, p. 122, tradução nossa) esclarece que:

\begin{abstract}
Seu objetivo, em ambos os casos, era criar formas análogas às das artes visuais por meios verbais, mas não através da mimese convencional. Stein rejeitava a narrativa, a descrição e o diálogo - o arsenal comum do escritor para a representação do mundo empírico fora do texto. Como qualquer escritor, ela iria observar; ela iria escutar; ela iria meditar. Então, em um ousado abandono do comportamento comum do escritor, ela iria organizar suas palavras como diversas pinceladas, frequentemente desafiando a gramática e, portanto, o significado, e organizando padrões que, em seu modo de pensar, correspondiam ao objeto ou à pessoa que havia inspirado a natureza-morta ou o retrato ${ }^{1}$.
\end{abstract}

Neste ato de distanciamento das formas já conhecidas da literatura em busca da criação de uma forma de expressão textual em ligação com as artes visuais, Stein desenvolveu uma escrita singular. Para um rápido panorama das características que permeiam tal escrita, abordamos a tese de Lavalle (2003), que desenvolve uma detalhada análise dos textos da escritora com foco em seus retratos literários. Apesar do recorte específico, os aspectos estudados também podem ser observados em linhas gerais nas demais categorias de escritos redigidos por Stein. Ao identificar e dissecar quatro grandes propriedades da escrita steiniana, Lavalle (2003) mostra de que maneira a poeta busca se expressar, manipulando a língua inglesa sob uma ótica bastante particular e a organizando de maneiras distintas das cotidianas. As qualidades analisadas por Lavalle (2003) são:

Primeiro: a repetição/insistência. Ao repetir palavras, frases e até mesmo parágrafos inteiros, Stein está buscando insistir para que surjam novas ênfases, novas possibilidades sonoras e

\footnotetext{
${ }^{1} \mathrm{Cf}$. o trecho original: "Her aim in both instances was to create analogs to visual forms by verbal means but not through conventional mimesis. Stein rejected narration, description, and dialogue - the writer's usual arsenal for the depiction of the experiential world outside the text. Like any writer, she would look; she would listen; she would meditate. Then in a daring departure from the usual writerly behavior, she would arrange her words like so many brushstrokes, often defying grammar and therefore meaning, and working out patterns that to her mind corresponded to the object or person that had instigated the still life or portrait."
} 
semânticas, modificação de minúcias acarretando o surgimento de toda uma nova visão sobre as palavras.

Segundo: o presente contínuo. Nos textos de Stein não há passado e nem futuro. Sem a intenção de descrever ou contar qualquer história, Stein manipula o tempo para que tudo se passe em um eterno presente. Um aqui/agora em constante atualização que busca apresentar algo no momento exato da sua percepção.

Terceiro: a colagem e a fragmentação. Stein joga com a simultaneidade de elementos díspares e com a associação de pensamentos não lógicos, pois os processos de colagem não seguem necessariamente um esquema cartesiano de combinação. Trabalha também com a mescla de diferentes pontos de vista de uma mesma situação colocados simultaneamente no texto, como em um quadro cubista, em que diversos planos da mesma coisa são expostos em um único.

Quarto: a montagem. Através da aglutinação de elementos que muitas vezes não contêm valor associativo algum, Stein monta seus textos com grande carga de tensão. Reordena a realidade em uma representação abstrata por meio do acúmulo de imagens e aproxima a percepção do espectador do processo de criação original pelo qual passou a artista.

Mediante esses principais atributos, a escrita steiniana se inventa como "uma linguagem que existe fora da sintaxe, das regras e, algumas vezes, fora até do vocabulário da língua inglesa, uma linguagem não tanto de comunicação quanto de expressão [...]" (LAVALLE, 2003, p. 145). Uma linguagem que coloca em xeque os usos linguísticos habituais para criar seu próprio funcionamento, não buscando descrever algo, mas sim buscando ser algo:

\footnotetext{
Usando a linguagem para negar nexos imediatos do significado ou da representação, G. Stein percebeu que deveria inventar um modo de mostrar aquilo sobre o que não se pode escrever - escrever sobre coisas, tentar explicá-las ou descrevê-las seria um procedimento típico do século XIX. [...] os retratos são discursos menos destinados a dizer, do que funcionar mostrando qualquer coisa. Assim, o termo 'invenção' é a chave para se compreender o potencial estético dos retratos [...] (LAVALLE, 2003, p. 148, grifo do autor).
}

Uma terceira categoria textual criada por Stein ao lado das naturezas-mortas e dos retratos literários é a peça-paisagem, sua escrita para o teatro. Assim como as duas anteriores, esta também toma aspectos emprestados das artes visuais. No entanto, enquanto as naturezas-mortas 
e os retratos adentram o campo da poesia, as peças-paisagem se inserem na dramaturgia. Sendo concebidas com o intuito de virem a ser vocalizadas na cena teatral.

\section{A PEÇA-PAISAGEM E A QUESTÃO DO SOM}

De acordo com Stein (1998), as peças que compõem sua segunda coletânea teatral, Operas and Plays, são peças-paisagem. Elucidando o conceito, a autora redige seu texto Plays, o qual foi preparado originalmente para uma das palestras de um ciclo que realizou nos Estados Unidos da América. Neste texto, Stein afirma que ao assistir o teatro de seu tempo sentia que a emoção da cena não acontecia em sincronia com a sua emoção como espectadora, havia uma síncope entre as duas. Fato que a fazia se sentir nervosa e inquieta ao assistir uma peça.

Seguindo com sua argumentação, Stein (1998) expõe que ao se ler um livro tem-se controle total do tempo da experiência que se terá com a obra. Você tem a possibilidade de permanecer o quanto desejar em um detalhe atrativo, ou então voltar e rever partes pelas quais já passou, ou ainda avançar para capítulos além, etc. No teatro isso não acontece. Há “[...] o inconveniente de nunca ser capaz de começar de novo porque antes de começar já havia terminado, e em nenhum momento você esteve pronto, nem para começar e nem para terminar" 2 (STEIN, 1998, p. 258, tradução nossa). A ação dramática corre independentemente do espectador, e não há como voltar no tempo e rever uma cena já feita para relembrar algo. Por isso é preciso estar constantemente trazendo à memória uma série de coisas: quem são as personagens, qual a relação entre elas, o que se passou nas cenas anteriores, entre outras. Isso se torna crucial para acompanhar o que está acontecendo no momento atual da peça. Mas, segundo a autora, este é um dos causadores da síncope entre a emoção da cena e a emoção do espectador. Os dois estão sempre caminhando em tempos diferentes: a peça seguindo em sua linearidade constante em contraposição à plateia, que está voltando sempre ao passado em memória para recobrar fatos e dados.

Outro aspecto colocado por Stein (1998) é que no teatro não há tempo suficiente para desenvolver uma familiaridade da obra com o público. Isso faz com que não haja excitação numa peça teatral, pois o que torna algo excitante é a quebra da expectativa (requer uma familiaridade

\footnotetext{
${ }^{2}$ Cf. o trecho original: "[...] the bother of never being able to begin over again because before it had commenced it was over, and at no time had you been ready, either to commence or to be over."
} 
prévia). Para a autora, na vida real, por exemplo, entre pessoas que já se conhecem, o que faz algo ser excitante é quando alguém age de forma inesperada. Como no teatro ela não conseguia se familiarizar com a obra e seus aspectos devido à maneira como ele ocorria, a excitação não acontecia. Ao fim da peça, ao invés de acabar com uma sensação de plenitude, Stein sentia alívio.

A estes dois fatores, Stein (1998) acrescenta que os aspectos visuais da peça a distraiam do texto falado e vice-versa. Considerava difícil acompanhar ambas as coisas em conjunto: “As coisas sobre as quais se tropeçava e eram coisas tanto de ver quanto de ouvir eram roupas, vozes, o que eles os atores diziam, como estavam vestidos e como isso tudo se relacionava com a movimentação"3 (STEIN, 1998, p. 258, tradução nossa). Toda essa combinação de elementos simultâneos em cena exigindo a atenção constante do espectador só fazia aumentar a síncope que Stein sentia entre palco e plateia.

Como um último ponto, Stein (1998) diz não haver utilidade alguma em uma peça contar mais uma história, dado que todos já sabem e contam muitas histórias. Deste modo, ela busca contar apenas a essência do ocorrido e afirma que a base de suas peças é como a essência de seus retratos (dos quais algumas características principais analisamos anteriormente). Neles, ela conta o que cada um é sem contar histórias. Nas peças, conta o que aconteceu, mas do mesmo modo, sem contar qualquer história.

Assim, Stein (1998) diz pensar o teatro a partir da visão e do som em relação com a emoção e o tempo muito mais do que com uma história e uma ação, e conclui que uma peça deve ser exatamente como uma paisagem: nada acontece, mas os elementos ali dispostos estão todos em relação uns com os outros. Não há uma história a ser contada, pois isso acarretaria a necessidade de constantemente trazer o passado à memória e de se preocupar com um futuro, sendo que "o negócio da Arte [...] é viver no presente atual, isto é o presente atual completo, e completamente expressar o presente atual”4 (STEIN, 1998, p. 251, tradução nossa). E argumenta, uma vez que não é necessário se tornar familiar com uma paisagem, pois os elementos estão ali completamente dados, não há o problema de a emoção da plateia estar à frente ou atrás da

\footnotetext{
${ }^{3} \mathrm{Cf}$. o trecho original: "The things over which one stumbled and there it was a matter both of seeing and of hearing were clothes, voices, what they the actors said, how they were dressed and how that related itself to their moving around."

${ }^{4}$ Cf. o trecho original: "The business of Art [...] is to live in the actual present, that is the complete actual present, and to completely express actual present."
} 
emoção da peça. Como uma síntese de todos estes pontos, tomamos um trecho da tese de Moreira (2007, p. 103) sobre a dramaturgia e o pensamento sobre o teatro de Gertrude Stein:

Ao eliminar da peça o enredo, a história e personagens carregados de subjetividade, passado, biografia, e ao passar a identificar uma peça à ideia de paisagem, Gertrude Stein teria então atingido seu objetivo de fazer da experiência de se assistir a uma peça, um momento no qual a emoção do público e os eventos no palco estarão comprometidos apenas com o presente no qual se desenrola a ação. Se não há história a ser contada, o espectador não precisa se preocupar com a memória do que se passou no palco, nem com a antecipação do que virá a acontecer. $O$ espectador apreende o momento como um todo, assim como o observador de uma paisagem.

Mas a aproximação operada por Stein entre seus textos para teatro e a ideia de uma paisagem nos leva para além da sua conexão com as artes visuais. Sua preocupação com o som do que escrevia é notável para qualquer leitor mais atento. A maneira como a autora trabalhava as palavras para fazer seus textos soarem das mais diversas formas a põe em conexão também com aspectos da arte sonora. Aos olhos (e ouvidos) de estudiosos de teatro da contemporaneidade, como Danan (2012, p. 135), fica claro que “em Stein, com efeito, 'a peça-paisagem' não é apenas imagem de uma paisagem. Ela é poema e (paradoxalmente) música".

Segundo a linguista Watson (2005), Stein aparentava ter uma forte consciência auditiva e se interessava em trabalhar com a sonoridade das palavras, seus ritmos e o movimento que descreviam. Para ela parecia ser muito importante, além disso, a questão das vozes e das inflexões, das ênfases e das acentuações. Stein brincava com a escrita, e "se não percebermos as 'Letras Barulhentas' de Stein [...], estaremos perdendo algo divertido, bem como matando o significado ou, falando de modo menos criminal, não dando tanta vida ao significado como poderíamos" ${ }^{5}$ (WATSON, 2005, p. 33, tradução nossa).

Assim, a preocupação de Stein com o som das inflexões, rítmicas, ênfases e acentuações daquilo que escrevia em seus textos compostos por repetições, fragmentações, colagens, montagens e em presente contínuo, faz com que suas dramaturgias apresentem grande potencial para formar sonoridades instigantes à audição. Talvez possamos afirmar que por meio disso tudo, as peças-paisagem de Gertrude Stein, quando montadas, podem se dar como instigantes paisagens sonoras, cujo conceito como concebido por Raymond Murray Schafer queremos agora abordar.

\footnotetext{
${ }^{5}$ Cf. o trecho original: "If we don't notice Stein's 'Loud Letters' [...], we are missing something fun, as well as killing meaning - or, less criminally, not bringing as much meaning to life as we could."
} 


\section{A PEÇA PAISAGEM, A PAISAGEM SONORA E A QUESTÃO DO RUÍDO}

Segundo o artista e pesquisador sonoro Obici (2008), no decorrer do século XX a atenção dos pesquisadores da música parece ter sido voltada de forma especial ao ambiente. "Diferentes compositores e pensadores abordaram o tema do ambiente sonoro em suas obras, seja como material de criação musical, seja sob a forma de tratados, manifestos, estudos e livros" (OBICl, 2008, p. 38). Dentre eles está o músico, professor e ambientalista Raymond Murray Schafer, que em seu livro A Afinação do Mundo realiza uma ampla análise dos sons que preenchem o ambiente habitado pelo ser humano desde a antiguidade até os dias atuais e cunha o termo paisagem sonora para se referir aos campos acústicos a que estamos expostos. Segundo ele, uma paisagem sonora é definida como:

\footnotetext{
O ambiente sonoro. Tecnicamente, qualquer porção do ambiente sonoro vista como um campo de estudos. O termo pode referir-se a ambientes reais ou a construções abstratas, como composições musicais e montagens de fitas, em particular quando consideradas como um ambiente (SCHAFER, 2001, p. 366).
}

Schafer, (2001, p. 23) acrescenta ainda: "Podemos isolar um ambiente acústico como um campo de estudo, do mesmo modo que podemos estudar as características de uma determinada paisagem". E, mais adiante em seu livro, complementa fazendo algumas relações entre a percepção visual e a sonora, afirmando que as distinções introduzidas pelos psicólogos da Gestalt entre figura e fundo e a noção de campo introduzida posteriormente pelos psicólogos da fenomenologia, podem ser feitas também em questões de som. A figura seria o som em primeiro plano em nossa percepção, aquele que está no foco de interesse; o fundo seria composto pelos sons em segundo plano, que preenchem o ambiente dando um contexto; e o campo seria a totalidade do ambiente acústico, a paisagem sonora em si. Assim, ao analisar os diversos sons que compõem uma paisagem sonora, seja ela natural ou produzida artificialmente, encontrada no dia a dia ou em situação extracotidiana, podemos estudá-la de forma análoga aos elementos que constituem uma paisagem visual, com a diferença de que se trata de eventos ouvidos, e não de elementos visualizados.

Isso nos permitiria estudar, por exemplo, a apresentação de uma peça de teatro como uma paisagem sonora, com estudo focado nos sons que compõem o espetáculo, tais quais, as falas dos atores, os sons ao se locomover, os efeitos sonoros criados em cena ou pré-gravados, as músicas constantes na peça, entre outros. Inclusive, mais aspectos poderiam interferir nesta 
paisagem, como o barulho da plateia e até o barulho provindo de fora da sala do teatro. Talvez estes últimos poderiam ser considerados como ruídos dentro do todo. Em sua análise das paisagens sonoras hodiernas, Schafer (2001) dá bastante atenção à questão do ruído, para o qual apresenta quatro definições: som não-desejado, som não-musical, qualquer som forte, distúrbio em qualquer sistema de sinais. O autor supracitado reconhece que o termo é um tanto quanto subjetivo, pois o que pode ser caracterizado como ruído por uma sociedade, pode não ser por outra, mas aponta para possíveis concordâncias gerais dentro de uma mesma cultura. Como exemplo de ruído atual, cita o crescente som das máquinas, dos aparelhos eletrônicos e dos grandes aglomerados de pessoas surgidos e intensificados a partir da Revolução Industrial.

Ao comentar as ideias de Schafer, Obici (2008, p. 43-44) coloca que os sons caracterizados como ruídos possuem grande importância principalmente para estudos na área da comunicação e da arte através da sua potência de criação, sua característica de ponto de instabilidade fértil e sua capacidade de ruptura com as estruturas de transmissão de códigos hegemônicos. Para Obici (2008), é necessário se posicionar diante da ruidosa sociedade contemporânea com uma atitude de escuta pronta a aproveitar as suas potencialidades. Exemplificando, cita que a música ocidental ampliou em muito seus horizontes a partir do momento em que passou a incluir em seu trabalho sons não pertencentes aos tratados estéticos tradicionais, então considerados como ruídos.

Assim, fica evidente a força que o ruído possui no campo da invenção artística. E Gertrude Stein parecia estar ciente dessa potencialidade criativa, pois as qualidades de seus textos muitas vezes deixam claro a cacofonia intencional que podem gerar. Tomando principalmente a quarta definição de ruído organizada por Schafer (2001), distúrbio em qualquer sistema de sinais, seria possível caracterizar os textos de Stein em muitas incidências como tal, pois realizam uma quebra com a transmissão linguística padrão. Se pensarmos, de modo bem isolado, nas enunciações de sua dramaturgia escrita como material para a criação de uma paisagem sonora e estudá-las em sua potencialidade fonética, é possível ver suas arrojadas construções gramaticais favorecerem a criação de sonoridades com tendência a alcançar o público por outros meios que não unicamente os dos sentidos lógicos e harmônicos da linguagem comum, muitas vezes criando verdadeiros labirintos de palavras por onde o espectador é levado a viajar. Pavis (2015, p. 138), ao se referir às peças de Stein e de alguns outros autores que compartilham de características semelhantes, afirma que 
[...] a partir do momento que um texto é poético (opaco) demais para figurar um referente, ele tende a cristalizar-se e a autocongelar-se [...]. Uma estrutura repetitiva de termos ou de parágrafos produz o mesmo efeito: não entendendo o texto ou a razão da repetição, o ouvinte fica sensível a uma enunciação de massas de palavras ou de frases [...].

Quando não há base sólida de entendimento para fixar-se devido a uma utilização não convencional da linguagem, o espectador pode receber o texto steiniano simplesmente como uma enorme gama de sons. Segundo Watson (2005, p. 70-71), a escrita de Stein se encaixa muitas vezes nesse campo onde um referente não se define, pois se dá através de uma ruidosa massa de signos, as quais tendem não a cancelar-se em favor de uma interpretação unívoca, mas sim a somar-se:

O contexto frequentemente apaga todos menos um dos possíveis sinais que uma palavra pode nos enviar. Mas as palavras de Stein mantêm seus muitos possíveis sinais, multiplicando ao invés de reduzindo as "ramificações finais" das suas palavras. A escrita de Stein embaralha a lista de correspondências do cérebro ${ }^{6}$ (WATSON, 2005, p. 71, tradução nossa).

Mas isso está longe de ser uma impossibilidade de fruição das peças de Stein. A própria autora relata que ainda jovem e conhecendo pouco do idioma francês, foi assistir a uma peça encenada por uma atriz francesa e foi capaz de apreciar o espetáculo apenas por meio da relação entre som e movimento: "[...] era tudo tão estrangeiro e a voz dela sendo tão variada e tudo sendo tão francês que eu pude descansar naquilo tranquila. [...] Foi para mim um prazer em movimento extremamente simples e direto"” (STEIN, 1998, p. 258-259, tradução nossa). Tal apontamento demonstra que a autora reconhece o prazer baseado simplesmente no ouvir e no ver, mesmo que um sentido completamente lógico não se faça claro durante a experiência. Quanto a características como essa, presentes na arte, o estudioso das poéticas da voz Paul Zumthor (2014, p. 64) lembra que o traço básico que define a comunicação poética é a tendência a gerar mais prazer do que informação, com a função informativa em segundo plano.

\footnotetext{
${ }^{6}$ Cf. o trecho original: "Context usually deletes all but one of the possible signals a word can send to us. But Stein's words keep their many possible signals, multiplying instead of reducing the 'end-ramifications' of her words. Stein's writing shuffles the brain's mailing lists."

${ }^{7} \mathrm{Cf}$. o trecho original: "[...] it was all so foreign and her voice being so varied and it all being so french I could rest in it untroubled. [...] It was for me a very simple direct and moving pleasure."
} 
Stein desenvolvia as sonoridades possíveis de seus textos a ponto de criarem por si só, independente do significado, um prazer pela escuta, organizando as palavras para a criação de mundos sônicos onde é capaz do ouvinte se perder por alguns momentos de qualquer semântica e apreciar o ruído que se tornam as enunciações, como veremos a seguir.

\section{A PEÇA PAISAGEM, A PAISAGEM SONORA E A QUESTÃO DO RUÍDO}

Analisaremos um trecho do texto da peça A List (Uma Lista, em tradução livre) a partir de algumas das características identificadas por Lavalle nas obras de Gertrude Stein e, em seguida, quanto à sua potencialidade sonora. Esta peça integra a coletânea Operas and Plays e foi citada como um dos exemplos de peça-paisagem por Stein em sua explanação Plays. Optamos por não traduzir o excerto para preservar a obra como originalmente pensada pela autora, tanto em suas opções gramaticais quanto na sonoridade das palavras escolhidas.

MARTHA If four are sitting at a table and one of them is lying upon it it does not make any difference. If bread and pomegranates are on a table and four are sitting at the table and one of them is leaning upon it it does not make any difference.

MARTHA It does not make any difference if four are seated at a table and one is leaning upon it.

MARYAS If five are seated at a table and there is bread on it and there are pomegranates on it and one of the five is leaning on the table it does not make any difference.

MARTHA If on a day that comes again and if we consider a day a week day it does come again if on a day that comes again and we consider every day to be a day that comes again it comes again then when accidentally when very accidentally every other day and every other day every other day and every other day that comes again and everyday comes again when accidentally every other day comes again, every other day comes again and every other and every day comes again and accidentally and every day and it comes again, a day comes again and a day in that way comes again.

MARYAS Accidentally in the morning and after that every evening and accidentally every evening and after that every morning and after that accidentally every morning and after that accidentally and after that every morning.

MARYAS After that accidentally. Accidentally after that.

MARYAS Accidentally after that. After that accidentally.

MARYAS

AND More Maryas and more Martha.

MARTHA 


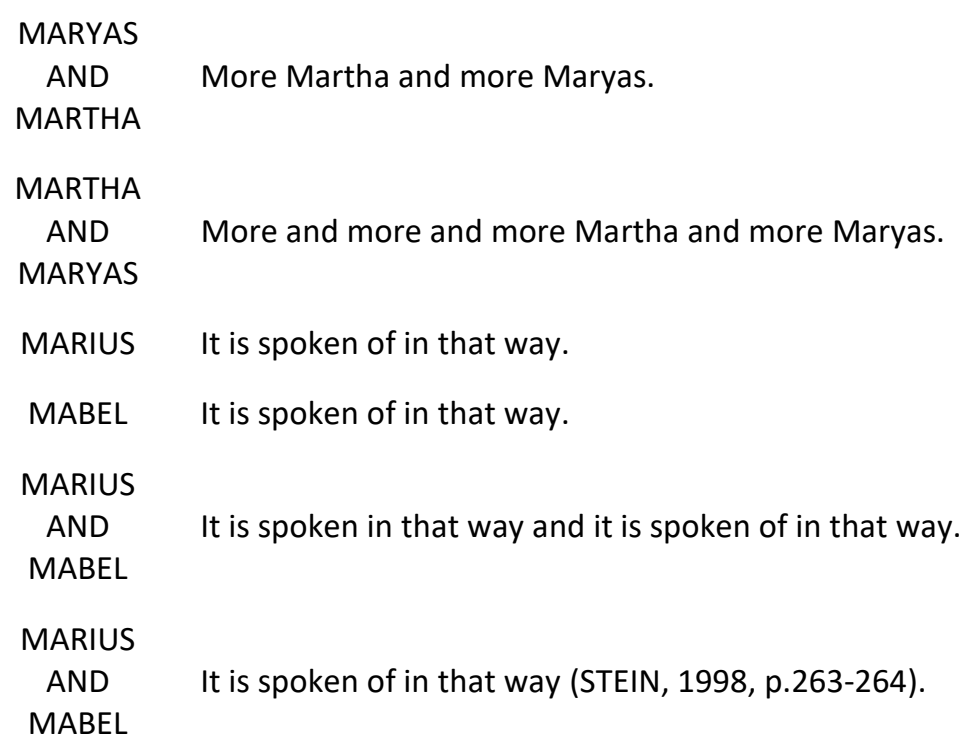

No início, a personagem Martha diz que se quatro pessoas estão sentadas ao redor de uma mesa e uma dessas pessoas estiver inclinada sobre o objeto, isso não faz diferença alguma, nem que sobre esta haja pão e romãs. Ela repete a afirmação e então a personagem Maryas adiciona à situação imaginada uma quinta pessoa, também sentada à mesa. Assim, Maryas também diz que o fato de uma delas estar inclinada sobre a mesa não faz diferença alguma. Após este trecho, Martha inicia uma grande sequência de repetições de frases e palavras com pequenas alterações ao longo do seu decorrer que parece considerar a possibilidade desta cena como descrita anteriormente acontecer novamente por acaso algum dia. E de novo em outro dia depois daquele. E assim sucessivamente. No entanto, a partir de certo ponto, não é possível mais saber ao certo se o que se considera passível de repetição é a cena da mesa ou a simples sucessão de dias. Então a outra personagem, Maryas, dá um pouco de continuidade para a sequência de repetições com a inserção de mais alguns detalhes relativos aos períodos dos dias. Termina as repetições em uma nova enunciação com uma sequência de duas frases, as quais são repetidas em ordem invertida pela mesma personagem na enunciação seguinte. Depois disso, acontece uma aparente mudança brusca de assunto. As duas personagens juntas dizem: "Mais Maryas e mais Martha" e então repetem a frase invertendo a posição dos seus nomes, de modo parecido com o que foi feito com as frases finais das repetições logo anteriormente. Em seguida, repetem outra vez triplicando a palavra "mais" no início da frase: "Mais e mais e mais Martha e mais Maryas". Após, nova mudança brusca de assunto. Agora são as personagens Marius e Mabel que falam. Marius diz que "É desse 
jeito que se fala disso". Mabel repete. Ambas dizem juntas que "É desse jeito que se fala isso e é desse jeito que se fala disso". Encerrando o excerto, repetem, agora juntas, a primeira frase de Marius.

Primeiro, chamamos a atenção para o fato de o texto inteiro acontecer no tempo presente. Não há a progressão de uma ação linear e ocorrem ações isoladas ao longo do trecho. Partimos das personagens falando sobre a hipótese de uma cena de pessoas à mesa e seguimos para a provável discussão sobre a possibilidade dessa cena se repetir outros dias (ou então simplesmente sobre a possibilidade da sucessão de dias se repetir constantemente). Depois, passamos para um jogo de enunciações com palavras ou frases que se repetem e podem ter suas ordens invertidas e terminamos com outros personagens dando afirmações sobre o que se fala e como se fala. Assim, o texto se constrói por meio da constante mudança de situações, sem que nenhuma tenha um desenvolvimento ou um fim. Este fato nos leva para a segunda questão a destacar deste excerto: as mudanças bruscas de assuntos, que parecem evidenciar uma característica de montagem da obra, em que temas não necessariamente apresentem ligação entre si surgem colocados em sequência. É possível perceber uma correlação quanto à forma e ao jogo gramatical entre as diferentes partes que compõem o trecho da peça, mas uma temática narrativa entre todas elas parece não existir. Pois, como diz Stein, relações entre as partes devem existir, mas não necessariamente serem do campo fabular:

\begin{abstract}
A paisagem tem a sua formação e assim afinal uma peça tem que ter formação e estar em relação uma coisa com a outra coisa e como a história não é a coisa já que qualquer um está sempre contando algo então a paisagem não se movendo mas estando sempre em relação, as árvores com as colinas as colinas com os campos as árvores entre si qualquer parte dela com qualquer céu e finalmente qualquer detalhe com qualquer outro detalhe, a história só tem importância se você gosta de contar ou gosta de ouvir uma história mas a relação está lá de qualquer maneira ${ }^{8}$ (STEIN, 1998, p. 264-265, tradução nossa).
\end{abstract}

Em terceiro lugar, as repetições de frases e palavras com seus ordenamentos mudando ao longo da enunciação fazem com que o significado também fique em constante mudança. É o que

\footnotetext{
${ }^{8} \mathrm{Cf}$. o trecho original: "The landscape has its formation and as after all a play has to have formation and be in relation one thing to the other thing and as the story is not the thing as any one is always telling something then the landscape not moving but being always in relation, the trees to the hills the hills to the fields the trees to each other any piece of it to any sky and then any detail to any other detail, the story is only of importance if you like to tell or like to hear a story but the relation is there anyway."
} 
acontece na terceira enunciação de Martha, a mais longa do excerto. Nela, parte da indecisão do significado gerada pelas repetições com trocas de ordens das palavras, se dá pelo fato de que a mesma palavra na língua inglesa pode ter significados diferentes dependendo do lugar da frase inserida. Por exemplo, a palavra "that" pode funcionar como pronome demonstrativo, conjunção ou advérbio, variando conforme as palavras que a antecedem ou sucedem. $O$ fato de Stein praticamente não utilizar pontuação durante todo este trecho, colabora ainda mais para que os significados se embaralhem, pois não é possível saber exatamente onde uma frase termina e outra começa. Tudo se torna um grande encadeamento de frases mescladas umas sobre as outras, denotando um aspecto de fragmentação.

Quanto às características sonoras possibilitados pelo texto, já na primeira enunciação de Martha é possível reparar algumas sutilezas, como as pequenas cacofonias geradas pela quantidade de letras " $\mathrm{t}$ " em palavras próximas: "sitting at a table", "sitting at the table", "upon it it does" (esta última pediria, tradicionalmente, uma vírgula entre as duas palavra iguais). A cacofonia se intensifica e chega ao seu auge um pouco mais adiante, na terceira enunciação de Martha. Ali a extensa repetição de palavras combinada com a quase ausência de pontuação cria uma sequência de ecos capaz de fazer com que o ouvinte perca completamente qualquer noção de significado. A enunciação inteira passa a operar como um bloco de sons ruidosos se remoldando a todo instante, com suas palavras sofrendo alterações de ênfase e se reencaixando de novas maneiras a cada repetição. Nesse trecho, um dos comentários de Hans-Thies Lehmann (2011, p. 104) sobre as peças-paisagem de Stein se faz sentir verdadeiramente: “Em um grau até então inaudito, [o texto de Stein] emancipa a oração em relação à frase, a palavra em relação à oração, o potencial fonético em relação ao potencial semântico, o som em relação ao sentido".

Após a intensa sequência de Martha, a características ruidosa do texto volta a um estado de sutilezas. Maryas perpetua um pouco a lógica de repetições e ecos da fala de Martha, mas de modo mais comportado e segue para as construções com detalhes cacofônicos menores como "Accidentally after that. After that accidentally", em que as duas palavras do início da segunda frase ecoam as duas do fim da primeira, ou então "More and more and more Martha and more Maryas", onde a pronúncia da palavra "more" repetidamente por Martha e Maryas ao mesmo tempo pode gerar um trava-língua e se enrolar com o nome das próprias personagens, que também começam com a letra "m". 
Por fim, as personagens Marius e Mabel trabalham com a repetição de uma única frase, apenas com a supressão de uma pequena palavra, "of", em seu meio em determinado momento, alterando o significado do conjunto, como visto há pouco. Estas enunciações finais parecem ser autorreferenciais, falando do próprio jogo gramatical em andamento e discutindo sobre as diferentes maneiras de enfatizar as frases e variar suas acentuações a partir de um mesmo texto. Em um recurso metalinguístico, as personagens parecem expor ainda mais as intenções de Stein pela exploração sonora de suas obras.

\section{CONSIDERAÇÕES FINAIS}

Para o dramaturgo francês Novarina (2009), ao ser lançada do interior do homem através da sua boca, a palavra é capaz de instaurar qualquer outra realidade. Ao atravessar o ar a palavra separa, esquarteja, divide a matéria para abri-la e revirá-la do avesso. "O espaço não se estende mas se escuta. [...] a linguagem é o lugar do aparecimento do espaço" (NOVARINA, 2009, p. 16, grifo do autor). A palavra constrói e desconstrói espaço e tempo, os multiplica e os sobrepõem em existência concomitante: espaço x tempo, escreve o dramaturgo, ao contrário do tradicional espaço-tempo, pois ambos são multiplicados, e o sinal desta operação, o " $x$ ", é o verbo que os age. Contudo, para o autor supracitado, não é qualquer palavra que é capaz de tanto. Para tal, é necessária a criação poética que não se propõe a trilhar as instâncias usuais da linguagem. É necessária a poesia que busca a todo o momento lapidar a pedra-bruta das palavras em novas formas, que rompa com a linearidade cronológica e geográfica do espaço e do tempo comumente pensados. É necessária a escrita que inventa novas possibilidades de uso para a linguagem:

Se procura reencontrar o movimento da língua - recolocá-la em desequilíbrio, religá-la. Porque há momentos em que, na nossa língua, na nossa fala, tem morte. Gelo. Imobilidade, estado cadavérico da linguagem. Um cadáver é terrível, um cadáver não se mexe... Também acontece com a língua de ser um cadáver. E não deve (NOVARINA, 2009, p. 20).

As dramaturgias de Gertrude Stein ativadas em cena por meio da voz podem ser capazes de operar este aparecimento do espaço sobre o qual o autor citado anteriormente discorre. A retirada da língua da inércia e a reinvenção das peças-paisagem de Stein, nos convidam a passear por intensas paisagens sonoras, verdadeiros mundos sônicos, os quais somos levados a observar a partir de diferentes ângulos, perspectivas e distâncias. Pois, segundo o dramaturgo e professor 
Joseph Danan (2012, p. 134, grifo do autor), "entendo que sou eu, leitor ou espectador, que cria o movimento no interior da paisagem e que liga os elementos em presença [...]". Mas o movimento não se dá unicamente pela parte do espectador, se dá em duas instâncias: a do ouvinte que se desloca através da paisagem com suas escolhas, e a das palavras que sustêm a paisagem em cena:

É zebrando e fulgurando, caindo, que a palavra emite o movimento: [...] a unidade do movimento é o verbo. Jogada, a palavra vibra: ela é seminal, espalhada, dispersada; ela semeia. As palavras emitem sentido em todos os sentidos. [...] Da fonte da linguagem brota sentido, quer dizer espaço - pois, por sentido, é preciso entender movimentos, ziguezagues, emoções, diretivas, voos, traçados antagônicos, ascensões contrastadas, queda na vertical, ovais direitas, diagonais do solo que desfalecem sob nossos pés de falantes (NOVARINA, 2009, p. 86-87, grifo do autor).

Assim, o espectador descreve um percurso próprio por meio das sonoridades que se constroem no teatro de Stein, em consciência ativa. De acordo com Zumthor (2014, p. 54), percursos como esse em obras artísticas são distintos para cada um por serem uma ocupação transitória das lacunas em branco das quais a obra é feita em um movimento nômade, pois o preenchimento feito em um dado instante pode ser modificado já no seguinte - a obra vibra e o leitor vibra junto com ela. Nos mundos criados por Stein, a imensa possibilidade de fruição dos vibrantes signos sonoros, nos mantém em constante movimento em relação a uma paisagem que é vista de modo específico por cada integrante da plateia, "a multiplicidade não permite reações uniformes nos leitores de Stein; somos prevenidos de nos tornarmos máquinas de ler e somos, dessa forma, mantidos vivos e conscientes" (WATSON, 2005, p. 71, tradução nossa).

Os textos steinianos vocalizados - com toda a sua gama de sonoridades incomuns construídas por meio de seus jogos de palavras e ritmos que podem ter seus sentidos alterados a cada repetição, com seus modos de composição textual desafiando o espaço e o tempo, com suas construções linguísticas inovadoras que realizam uma quebra da transmissão convencional da informação - muitas vezes atingem a condição de ruído. Seja pela miríade semântica, pela maneira como são arranjadas, as palavras são trabalhadas de forma a perder seu significado primeiro e a atingir o espectador como uma torrente de sonoridades com repetições, ecos, aliterações, etc. As peças de Stein desarmam o público dos métodos comuns de fruição e o coloca livre em meio a um ambiente sonoro completamente desconhecido, onde nem sempre é possível encontrar em que se agarrar ao nível semântico, mas onde sempre haverá um contato do sensível minuciosamente 
pensado para que se crie uma experiência do campo da alteridade. Vivenciar uma peça-paisagem de Gertrude Stein nunca é trilhar duas vezes o mesmo caminho. É se perder em um mundo sônico. É percorrer uma paisagem sonora em perpétua modificação, onde cada instante apresenta uma nova bifurcação.

\section{REFERÊNCIAS}

BOWERS, Jane Palatini. The composition that all the world can see: Gertrude Stein's theater landscapes. In: FUCHS, Elinor; CHAUDHURI, Una (Org.). Land/Scape/Theater. Ann Arbor: University of Michigan Press, 2002, p. 121-144.

DANAN, Joseph. Peça-paisagem. In: SARRAZAC, Jean-Pierre (Org.). Léxico do drama moderno e contemporâneo. São Paulo: Cosac Naify, 2012, p. 134-135.

LEHMANN, Hans-Thies. Teatro pós-dramático. 2. ed. São Paulo: Cosac Naify, 2011.

LAVALLE, Luci Maria Collin. A composição em movimento: a dinâmica temporal e visual nos retratos literários de Gertrude Stein. 2003. 213 f. Tese (Doutorado em Estudos Linguísticos e Literários em Inglês) - Departamento de Letras Modernas, Universidade de São Paulo, 2003.

MOREIRA, Inês Cardoso Martins. Aqui há uma margem: teatro e exílio em Gertrude Stein. 2007. $401 \mathrm{f}$. Tese (Doutorado em Teatro) - Centro de Letras e Artes, Universidade Federal do Rio de Janeiro, 2007.

NOVARINA, Valère. Diante da palavra. Tradução de Angela Leite Lopes. 2. ed. Rio de Janeiro: 7 Letras, 2009.

$\mathrm{OBICl}$, Giuliano Lamberti. Condição da escuta: mídias e territórios sonoros. Rio de Janeiro: 7 Letras, 2008.

PAVIS, Patrice. Dicionário de teatro. 3. ed. São Paulo: Perspectiva, 2015.

SCHAFER, Raymond Murray. A afinação do mundo: uma exploração pioneira pela história passada e pelo atual estado do mais negligenciado aspecto do nosso ambiente: a paisagem sonora.

Tradução de Marisa Trench Fonterrada. São Paulo: Editora UNESP, 2001.

STEIN, Gertrude. Plays. In: CHESSMAN, Harriet; STIMPSON, Catharine R. (Org.). Stein: Writings 1932-1946. New York: Library of America, 1998, p.244-269.

WATSON, Dana Cairns. Gertrude Stein and the essence of what happens. Nashville: Vanderbilt University Press, 2005.

ZUMTHOR, Paul. Performance, recepção e leitura. 2. ed. São Paulo: Cosac Naify, 2014. 